Fetal Diagnosis

and Therapy
Fetal Diagn Ther 2010;28:9-13

DOI: $10.1159 / 000315295$
Received: April 27, 2010

Accepted after revision: May 18, 2010

Published online: July 21, 2010

\title{
Effect of Chorionic Villus Sampling on Uterine Artery Doppler
}

\author{
Asma Khalil ${ }^{a}$ Ranjit Akolekar ${ }^{\mathrm{b}} \quad$ Argyro Syngelaki $^{\mathrm{b}} \quad$ Jose-Maria Perez Penco ${ }^{\mathrm{a}} \mathrm{b}$ \\ Kypros H. Nicolaides ${ }^{a, b}$ \\ ${ }^{a}$ Department of Fetal Medicine, Institute for Women's Health, University College Hospital, and \\ ${ }^{b}$ Department of Fetal Medicine, King's College Hospital, London, UK
}

Key Words

Doppler $\cdot$ Uterine artery $\cdot$ Chorionic villus sampling

\begin{abstract}
Introduction: The aim of this study was to examine the potential effect of chorionic villus sampling (CVS) on placental perfusion by examining the change in uterine artery pulsatility index (PI) between the first and second trimesters of pregnancy. Materials and Methods: This was a prospective screening study for pregnancy complications which included measurement of uterine artery $\mathrm{Pl}$ at $11^{+0}$ to $13^{+6}$ weeks and at $20^{+0}$ to $24^{+6}$ weeks of gestation. In women at increased risk for fetal aneuploidies, CVS was performed. Uterine artery $\mathrm{Pl}$ in the first and second trimesters, and the change in $\mathrm{Pl}$ between the two examinations were compared between the CVS and non-CVS groups. Results: The study population included 8,822 singleton pregnancies, in 308 of which CVS was performed. In the CVS group, compared to the non-CVS group, the median uterine artery PI before CVS, corrected for gestational age, was higher in both the first and second trimesters of pregnancy, but the change in PI between the two examinations was not significantly different $(p=0.789)$. Conclusion: The performance of CVS in the first trimester is unlikely to interfere with normal placentation.

Copyright $\odot 2010$ S. Karger AG, Basel
\end{abstract}

\section{Introduction}

Chorionic villus sampling (CVS) is associated with placental damage with consequent miscarriage in around $1 \%$ of cases $[1,2]$. There is also some evidence that the CVS-related placental damage can cause fetal limb reduction defects when the procedure is performed before 10 weeks of gestation [3]. Some studies reported that CVS is associated with an increased risk of subsequent development of preeclampsia (PE) [4-7] and suggested that this might be related to placental damage caused by the invasive procedure. Suggested mechanisms for such an association include the following CVS-related consequences: (a) focal placental hemorrhage and inflammation resulting in reduced placental perfusion, (b) release of paternally derived fetal antigens stimulating a maternal immune response and endothelial dysfunction, and (c) alteration in the balance of angiogenic and antiangiogenic placental products, such as PlGF, VEGF and sFlt-1, which are known to play a role in the pathophysiology of PE $[5,6,8]$.

Extensive evidence suggests that $\mathrm{PE}$ is a consequence of impaired trophoblastic invasion of the maternal spiral arteries and their physiological conversion into large non-muscular low-resistance channels $[9,10]$. Such impairment is reflected in increased pulsatility index (PI) in

\section{KARGER}

Fax +41613061234 E-Mail karger@karger.ch www.karger.com
Asma Khalil

Department of Fetal Medicine, Institute for Women's Health

University College Hospital

London WC1E 6AU (UK)

Tel. +44 791740 0164, Fax +44 207034 8989, E-Mail asmakhalil79@googlemail.com 
the waveforms obtained from the uterine arteries by Doppler ultrasound [11-13]. In normal pregnancies uterine artery PI decreases between the first and second trimesters, but this fall is less in pregnancies that develop PE $[14,15]$. One study investigated the short-term effect of CVS on uterine artery PI and reported that in 17 women undergoing CVS there was no significant change in PI measured before and at 10 and $60 \mathrm{~min}$ after the procedure [16].

The aim of this study was to investigate the potential long-term effects of CVS on placental perfusion by examining the change in uterine artery PI between the first and second trimesters of pregnancy.

\section{Materials and Methods}

This was a prospective screening study for pregnancy complications which included measurement of uterine artery PI at $11^{+0}$ to $13^{+6}$ weeks and at $20^{+0}$ to $24^{+6}$ weeks of gestation. The study was approved by the King's College Hospital Ethics Committee and all participants gave their written informed consent. The entry criteria for this study were a singleton pregnancy with a live fetus at $11^{+0}$ to $13^{+6}$ weeks and surviving to beyond 23 weeks of gestation and who had measurements of uterine artery Doppler at $11^{+0}$ to $13^{+6}$ weeks and at $20^{+0}$ to $24^{+6}$ weeks. We excluded pregnancies resulting in miscarriage, those with fetal aneuploidies or major defects, terminations for psychosocial reasons, those with unknown pregnancy outcome and those who had an amniocentesis.

In the first trimester, women had combined screening for chromosomal abnormalities which involved an ultrasound scan to measure fetal crown-rump length (CRL) and nuchal translucency (NT) thickness, and measurement of maternal serum concentration of pregnancy-associated plasma protein-A (PAPP-A) and free $\beta$-human chorionic gonadotropin ( $\beta$-hCG; Delfia Xpress Analyzer; Perkin Elmer Life and Analytical Sciences, Waltham, Mass., USA). The results of maternal age, fetal NT, and serum free $\beta$-hCG and PAPP-A were used to estimate the patient-specific risk for trisomy $21[17,18]$. Gestational age was determined from the measurement of fetal CRL [19]. Women identified as being at high risk of chromosomal defects were offered CVS for fetal karyotyping. In all cases, CVS was performed after the measurement of uterine artery PI. The method of CVS was transabdominal and involved the ultrasound-guided insertion into the placenta of an $18-\mathrm{G}$ needle after the administration of local anesthesia (lidocaine 1\%) to the abdominal wall.

In the second trimester, a detailed ultrasound examination was carried out for assessment of fetal growth and the diagnosis of major fetal defects. Uterine artery Doppler was performed in both the first- and second-trimester scans. In the first trimester, a sagittal section of the uterus was obtained and the cervical canal and the internal cervical os was identified, as previously described [20]. The transducer was then gently tilted from side to side and color-flow mapping was used to identify each uterine artery adjacent to the cervix and uterus at the level of the internal os. Pulsed wave Doppler was used with the sampling gate set at $2 \mathrm{~mm}$ to cover the whole vessel and care was taken to ensure that the angle of insonation was less than $30^{\circ}$. When three similar consecutive waveforms were obtained, the PI was measured and the mean PI of the left and right arteries calculated. In the second trimester, the mean uterine artery PI was measured transvaginally because, at the same time, we measured cervical length to assess the risk of preterm delivery. All Doppler studies were carried out by sonographers who had received the Certificate of Competence in Doppler of the Fetal Medicine Foundation (www.fetalmedicine.com).

The ultrasound findings and patient characteristics, including demographic data and obstetric and medical history, were entered into a computer database. At the first trimester visit, women were asked to complete a questionnaire on age, racial origin (Caucasian, African, South Asian, East Asian or mixed), cigarette smoking during pregnancy (yes or no), method of conception (spontaneous, assisted), medical history of chronic hypertension (yes or no), parity (parous or nulliparous - if no delivery beyond $23^{+6}$ weeks), obstetric history (including previous pregnancy with $\mathrm{PE}$ ) and family history of PE in the mother (yes or no). The questionnaire was then reviewed by a doctor together with the woman. The maternal weight and height and body mass index were measured.

Data on pregnancy outcomes were obtained from the computerized maternity unit records.

\section{Statistical Analysis}

Maternal and fetal characteristics in the CVS and non-CVS groups were compared using the $\chi^{2}$ test for categorical variables and the Mann-Whitney test for continuous variables. The data on uterine artery mean PI were made Gaussian after logarithmic transformation. Regression analysis was used to determine the significance of the association between uterine artery mean PI and gestational age in both the first and second trimesters. Delta values of first- and second-trimester mean PIs for each patient were then calculated as the difference from the expected mean for gestation. The ratio of the delta value of mean PI in the second trimester to the delta value in the first trimester was calculated for each patient. The Mann-Whitney test was used to determine the significance of differences in the median delta ratios of the CVS and non-CVS groups.

Multiple regression analysis was used to determine whether CVS had a significant contribution in predicting uterine artery PI in addition to maternal and pregnancy characteristics. The statistical software package SPSS 16.0 (SPSS Inc., Chicago, Ill., USA) was used for data analysis.

\section{Results}

During the study period (March 2006 to August 2009), uterine artery Doppler at both $11^{+0}$ to $13^{+6}$ and $20^{+0}$ to $24^{+6}$ weeks of gestation was performed in 9,340 women but 518 were excluded from the study because they had amniocentesis $(\mathrm{n}=63)$, fetal aneuploidies or major defects $(n=18)$, they resulted in miscarriage $(n=10)$, or the pregnancy outcome was unknown $(\mathrm{n}=427)$. We included 8,822 cases and in 308 of these CVS was performed. In the CVS group, 12 women (3.9\%) developed PE compared with 283 women (3.3\%) in the non-CVS group. 
Table 1. Maternal and pregnancy characteristics in the CVS and non-CVS groups

\begin{tabular}{|c|c|c|}
\hline Maternal and pregnancy characteristics & $\begin{array}{l}\text { Non-CVS group } \\
(\mathrm{n}=8,514)\end{array}$ & $\begin{array}{l}\text { CVS group } \\
(\mathrm{n}=308)\end{array}$ \\
\hline Maternal age in years, median (IQR) & $31.6(27.2-35.3)$ & $35.5(30.9-39.8)^{*}$ \\
\hline Body mass index, median (IQR) & $24.2(21.9-27.6)$ & $24.2(21.7-26.9)$ \\
\hline Gestation at screening (days), median (IQR) & $12.7(12.3-13.1)$ & $12.7(12.3-13.2)$ \\
\hline \multicolumn{3}{|l|}{ Racial origins, $\mathrm{n}(\%)$} \\
\hline Caucasian & $4,837(56.8)$ & $201(65.3)$ \\
\hline African & $2,832(33.3)$ & $74(24.0)^{*}$ \\
\hline South Asian & $354(4.2)$ & $13(4.2)$ \\
\hline East Asian & $159(1.9)$ & $12(3.9)^{*}$ \\
\hline Mixed & $332(3.9)$ & $8(2.6)$ \\
\hline \multicolumn{3}{|l|}{ Parity, n (\%) } \\
\hline Nulliparous & $4,529(53.2)$ & $135(43.8)$ \\
\hline Parous - no previous PE & $3,702(43.5)$ & $158(51.3)^{*}$ \\
\hline Parous - previous PE & $283(3.3)$ & $15(4.9)$ \\
\hline Family history of PE, n (\%) & $379(4.5)$ & $9(2.9)$ \\
\hline Cigarette smoker, n (\%) & $589(6.9)$ & $19(6.2)$ \\
\hline \multicolumn{3}{|l|}{ Conception, $\mathrm{n}(\%)$} \\
\hline Spontaneous & $8,214(96.5)$ & $275(89.3)$ \\
\hline Assisted conception & $300(3.5)$ & $33(10.7)^{*}$ \\
\hline History of chronic hypertension, $\mathrm{n}(\%)$ & $132(1.6)$ & $7(2.3)$ \\
\hline Serum PAPP-A MoM, median (IQR) & $1.04(0.72-1.47)$ & $0.64(0.36-1.05)^{*}$ \\
\hline Serum free $\beta$-hCG MoM, median (IQR) & $1.00(0.68-1.51)$ & $1.14(0.74-2.14)^{*}$ \\
\hline Development of PE, n (\%) & $283(3.3)$ & $12(3.9)$ \\
\hline Gestation at delivery in weeks, median (IQR) & $39.6(38.7-40.6)$ & $40.0(39.0-40.9)$ \\
\hline
\end{tabular}

Comparisons between outcome groups ( $\chi^{2}$ test for categorical variables and Mann-Whitney test for continuous variables): ${ }^{*} \mathrm{p}<0.05$.

Table 2. Median and interquartile range of uterine artery mean PI in the first and second trimesters of pregnancy in the CVS and non-CVS groups

\begin{tabular}{lll}
\hline Uterine artery PI & $\begin{array}{l}\text { Non-CVS group } \\
(\mathrm{n}=8,514)\end{array}$ & $\begin{array}{l}\text { CVS group } \\
\text { (n=308) }\end{array}$ \\
\hline $\begin{array}{l}\text { Uterine artery PI - first trimester } \\
\quad \text { Delta value }\end{array}$ & $0.03(-0.26$ to 0.38$)$ & $0.14(-0.18 \text { to } 0.53)^{*}$ \\
$\quad$ Raw value & $1.64(1.33$ to 1.99$)$ & $1.72(1.42 \text { to } 2.12)^{*}$ \\
$\quad \begin{array}{l}\text { Uterine artery PI - second-trimester } \\
\quad \text { Delta value }\end{array}$ & $0.00(-0.16$ to 0.19$)$ & $0.07(-0.10 \text { to } 0.25)^{*}$ \\
$\quad$ Raw value & $1.03(0.87$ to 1.22$)$ & $1.10(0.92 \text { to } 1.27)^{*}$ \\
Delta second trimester/delta first trimester & $0.27(-0.22$ to 0.75$)$ & $0.26(-0.23$ to 0.78$)$
\end{tabular}

Comparisons between groups by the Mann-Whitney test: significance value * $\mathrm{p}<0.05$.

The maternal and pregnancy characteristics of the CVS and non-CVS groups are compared in table 1 . In the CVS group, the median maternal age was higher, there were fewer women of African racial origin, more women had assisted conception, the median maternal serum PAPP-A was lower and free $\beta$-hCG was higher.

CVS and Uterine Artery Doppler
In the CVS group, compared to the non-CVS group, the median delta uterine artery mean PI was higher in both the first and second trimesters of pregnancy (table 2). However, multiple regression analysis demonstrated that CVS did not have a significant contribution in predicting uterine artery PI in addition to maternal and 
Table 3. Multiple regression analysis to determine the maternal and pregnancy characteristics contributing significantly to the prediction of log uterine artery mean PI in the first and second trimesters of pregnancy

\begin{tabular}{lcccc}
\hline Characteristic & Coefficient & t statistic & p value & 95\% CI \\
\hline First trimester & & & & \\
$\quad$ Maternal age & -0.001 & -3.850 & $<0.0001$ & -0.001 to $4.5 \mathrm{e}-04$ \\
$\quad$ Body mass index & -0.002 & -5.633 & $<0.0001$ & -0.002 to -0.001 \\
African racial origin & 0.029 & 9.352 & $<0.0001$ & 0.023 to 0.035 \\
Mixed racial origin & 0.025 & 3.564 & $<0.0001$ & 0.011 to 0.039 \\
Gestational age & -0.029 & -12.163 & $<0.0001$ & -0.033 to -0.024 \\
log PAPP-A MoM & -0.084 & -14.692 & $<0.0001$ & -0.094 to -0.073 \\
Second trimester & & & & \\
Maternal age & $-4.2 \mathrm{e}-04$ & -2.086 & 0.037 & $-8.2 \mathrm{e}-04$ to $-2.5 \mathrm{e}-05$ \\
Body mass index & $7.1 \mathrm{e}-04$ & 2.939 & 0.003 & $2.3 \mathrm{e}-04$ to 0.001 \\
Smoking status & 0.012 & 2.556 & 0.011 & 0.003 to 0.020 \\
African racial origin & 0.017 & 6.293 & $<0.0001$ & 0.012 to 0.022 \\
South Asian racial origin & -0.015 & -2.539 & 0.011 & -0.026 to -0.003 \\
East Asian racial origin & -0.023 & -2.871 & 0.004 & -0.040 to -0.008 \\
Gestational age & -0.010 & -5.782 & $<0.0001$ & -0.013 to -0.006 \\
log PAPP-A MoM & -0.090 & -18.49 & $<0.0001$ & -0.099 to -0.080 \\
log free $\beta$-hCG MoM & -0.023 & -5.184 & $<0.0001$ & -0.031 to -0.008 \\
\hline
\end{tabular}

pregnancy characteristics (table 3). In the first trimester, the following factors made a significant contribution to the prediction of log uterine artery PI: maternal age, BMI, African and mixed racial origin, gestational age, and log PAPP-A MoM, but the following factors did not: smoking status $(\mathrm{p}=0.065)$, assisted conception $(\mathrm{p}=0.468)$, delta $\mathrm{NT}(\mathrm{p}=0.573), \log$ free $\beta$-hCG MoM ( $\mathrm{p}=0.344)$, and CVS $(p=0.059)$. In the second trimester, the following factors made a significant contribution to the prediction of $\log$ uterine artery PI: maternal age, BMI, smoking status, African, South Asian and East Asian racial origin, gestational age, log PAPP-A MoM, and log free $\beta$-hCG MoM, but the following factors did not: delta NT $(p=0.391)$ and CVS ( $\mathrm{p}=0.361)$.

In the CVS group, compared to the non-CVS group, the median delta uterine artery mean PI was higher in both the first and second trimesters of pregnancy, but the ratio of delta PI in the second to the first trimester was not significantly different $(\mathrm{p}=0.789$, table 2$)$.

\section{Discussion}

The results of our study demonstrate that the performance of CVS in the first trimester has no significant effect on the change in uterine artery mean PI between the first and second trimesters of pregnancy. These findings do not support the hypothesis that CVS leads to placental disruption and alteration in placental perfusion that is detectable by uterine artery Doppler.

Some studies reported that the incidence of $\mathrm{PE}$ in women having CVS is higher than in controls who had either amniocentesis or no invasive test and this led to the suggestion that CVS contributes to the development of $\mathrm{PE}$ [4-7]. A more likely explanation for this association is that the same components of screening leading to increased risk for chromosomal defects and therefore the uptake of CVS, such as increased maternal age and decreased serum PAPP-A, are also associated with increased risk of PE [21]. As shown in this study, in the CVS group compared to the non-CVS group, the uterine artery PI was higher in both the first trimester before the CVS and in the second trimester of pregnancy, and this increase was due to maternal and pregnancy characteristics, rather than to the invasive procedure per se. The women in the CVS group were older and had lower serum PAPP-A, factors which are known to be associated with increased uterine artery PI [22].

In normal pregnancy, trophoblastic invasion of the maternal spiral arteries continues during both the first and second trimesters and this is reflected in a fall in uterine artery PI with gestation which reaches a plateau at around 24 weeks [11-13, 23]. In women with impaired placentation, who are therefore at increased risk of developing PE, there is attenuation of the normal fall in uterine artery PI from the first to the second trimester $[14,15]$. 
Our study demonstrates that CVS is not associated with such attenuation of the fall in uterine artery PI with gestation. We conclude, therefore, that a CVS procedure in the first trimester is unlikely to interfere with normal placentation.

\section{Acknowledgment}

The study was supported by a grant from The Fetal Medicine Foundation (UK Charity No. 1037116).

\section{References}

1 Tabor A, Alfirevic Z: Update on procedurerelated risks for prenatal diagnosis techniques. Fetal Diagn Ther 2010;27:1-7.

2 Tabor A, Vestergaard CH, Lidegaard Ø: Fetal loss rate after chorionic villus sampling and amniocentesis: an 11-year national registry study. Ultrasound Obstet Gynecol 2009;34: 19-24.

- 3 Firth HV, Boyd PA, Chamberlain P: Severe limb abnormalities after chorion villus sampling at 56-66 days of gestation. Lancet 1991; $337: 762-763$.

4 Philip J, Silver RK, Wilson RD, Thom EA, Zachary JM, Mohide P, Mahoney MJ, Simpson JL, Platt LD, Pergament E, Hershey D, Filkins K, Johnson A, Shulman LP, Bang J, MacGregor S, Smith JR, Shaw D, Wapner RJ, Jackson LG, NICHD EATA Trial Group: Late first trimester invasive prenatal diagnosis: results of an international randomized trial. Obstet Gynecol 2004;103:1164-1173.

5 Silver RK, Wilson RD, Philip J, Thom EA, Zachary JM, Mohide P, Mahoney MJ, Simpson JL, Platt LD, Pergament E, Hershey D, Filkins K, Johnson A, Wapner RJ, Jackson LG, NICHD EATA Trial Group: Late first trimester placental disruption and subsequent gestational hypertension/preeclampsia. Obstet Gynecol 2005;105:587-592.

-6 Adusumalli J, Han CS, Beckham S, Bartholomew ML, Williams J III: Chorionic villus sampling and risk for hypertensive disorders of pregnancy. Am J Obstet Gynecol 2007;196:591.e1-591.e7.

7 Grobman WA, Auger M, Shulman LP, Elias S: The association between chorionic villus sampling and preeclampsia. Prenat Diagn 2009;29:800-803.
8 McKeeman GC, Ardill JE, Caldwell CM, Hunter AJ, McClure N: Soluble vascular endothelial growth factor receptor-1 (sFlt-1) is increased throughout gestation in patients who have preeclampsia develop. Am J Obstet Gynecol 2004;191:1240-1246.

9 Brosens JJ, Pijnenborg R, Brosens IA: The myometrial junctional zone spiral arteries in normal and abnormal pregnancies: a review of the literature. Am J Obstet Gynecol 2002; 187:1416-1423.

10 Meekins JW, Pijnenborg R, Hanssens M, McFadyen IR, van Asshe A: A study of placental bed spiral arteries and trophoblast invasion in normal and severe pre-eclamptic pregnancies. Br J Obstet Gynaecol 1994;101:669674.

11 Jauniaux E, Jurkovic D, Campbell S: In vivo investigations of the anatomy and the physiology of early human placental circulations. Ultrasound Obstet Gynecol 1991;1:435-445.

12 Jurkovic D, Jauniaux E, Kurjak A, Hustin J, Campbell S, Nicolaides KH: Transvaginal color Doppler assessment of the uteroplacental circulation in early pregnancy. Obstet Gynecol 1991;77:365-369.

13 Kaminopetros P, Higueras MT, Nicolaides $\mathrm{KH}$ : Doppler study of uterine artery blood flow: comparison of findings in the first and second trimesters of pregnancy. Fetal Diagn Ther 1991;6:58-64.

14 Gómez O, Figueras F, Martínez JM, del Río M, Palacio M, Eixarch E, Puerto B, Coll O, Cararach V, Vanrell JA: Sequential changes in uterine artery blood flow pattern between the first and second trimesters of gestation in relation to pregnancy outcome. Ultrasound Obstet Gynecol 2006;28:802-808.

-15 Plasencia W, Maiz N, Poon L, Yu C, Nicolaides $\mathrm{KH}$ : Uterine artery Doppler at $11^{+0}$ to $13^{+6}$ weeks and $21^{+0}$ to $24^{+6}$ weeks in the prediction of pre-eclampsia. Ultrasound Obstet Gynecol 2008;32:138-146.
16 Cohen-Overbeek TE, Jahoda MG, Wladimiroff JW: Uterine bloodflow velocity waveforms before and after transcervical chorionic villus sampling. Ultrasound Med Biol 1990;16:129-132.

$\checkmark 17$ Kagan KO, Wright D, Baker A, Sahota D, Nicolaides KH: Screening for trisomy 21 by maternal age, fetal nuchal translucency thickness, free beta-human chorionic gonadotropin, and pregnancy associated plasma protein-A. Ultrasound Obstet Gynecol 2008;31:618-624.

18 Snijders RJ, Noble P, Sebire N, Souka A, Nicolaides KH: UK multicentre project on assessment of risk of trisomy 21 by maternal age and fetal nuchal-translucency thickness at 10-14 weeks of gestation. Fetal Medicine Foundation First Trimester Screening Group. Lancet 1998;352:343-346.

19 Robinson HP, Fleming JE: A critical evaluation of sonar 'crown-rump length' measurements. Br J Obstet Gynaecol 1975;82:702710.

20 Martin AM, Bindra R, Curcio P, Cicero S, Nicolaides KH: Screening for pre-eclampsia and fetal growth restriction by uterine artery Doppler at 11-14 weeks of gestation. Ultrasound Obstet Gynecol 2001;18:583-586.

21 Staboulidou I, Galindo A, Maiz N, Karagiannis G, Nicolaides KH: First trimester uterine artery Doppler and serum pregnancy-associated plasma protein-A in preeclampsia and chromosomal defects. Fetal Diagn Ther 2009;25:336-339.

22 Plasencia W, Maiz N, Bonino S, Kaihura C, Nicolaides KH: Uterine artery Doppler at $11+0$ to $13+6$ weeks in the prediction of preeclampsia. Ultrasound Obstet Gynecol. 2007;30:742-749.

23 Bewley S, Campbell S, Cooper D: Uteroplacental Doppler flow velocity waveforms in the second trimester: a complex circulation. Br J Obstet Gynaecol 1989;96:1040-1046. 